and its inhibitory powers compared with those of the parent acid and amide by in vitro tests analogous to those previously described ${ }^{1,2}$. The compound was found less active than the simple acid and amide.

In terms of the theory ${ }^{3}$ on the basis of which pyridine-3-sulphonic acid was first investigated, which relates several inhibitory compounds to definite structures (for example, $p$-aminobenzoic acid, nicotinic acid) of importance to the organisms concerned, such failure to produce a more active compound can readily be understood. There is considerable specificity between the mutual effects of $p$-aminobenzoic acid and sulphanilamide, and between nicotinic acid and pyridine-3-sulphonic acid. $M . \& B .693$ is possibly related equally specifically to a derivative of $p$-aminobenzoic acid. Unless, therefore, the natural nicotinic acid derivatives are similar to those of $p$-aminobenzoic acid, it is unlikely that a group which enhances the activity of sulphanilamide will enhance that of pyridine-3-sulphonic acid.

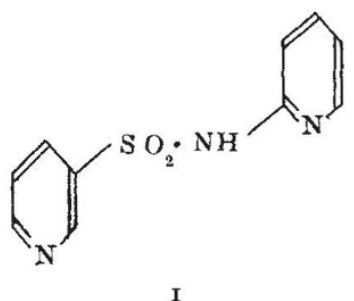

Instances of failure to produce more active 'hybrids' in this manner are common in chemotherapeutic literature; for example, among sulphanilamide derivatives themselves, diethylaminoalkyl ${ }^{4}$, quinoline $^{5}$, tropinone ${ }^{6}$ and dihydrocuprein ${ }^{6}$ derivatives are described as of relatively little activity, and hybrids between quinine and emetine? have not the activity of optimal members of the component series. It is suggested that the reason for such lack of success may be the same as in the case of the present pyridyl compound. Though corresponding essential metabolites are not in these cases known, it is not likely that they will be closely related to one another ; known essential metabolites, for example, the vitamins, are very diverse in structure.

Preparation of $(I)$. Pyridine-3-sulphonyl chloride (from $2.5 \mathrm{gm}$. of the acid) and 2-aminopyridine (1.5 gm. ; I am indebted to Dr. A. J. Ewins for this material) were mixed in pyridine $(5 \mathrm{ml}$.), warmed a.t $100^{\circ}$ for $\frac{1}{2} \mathrm{hr}$. and water $(20 \mathrm{ml}$.) added. The product separated on cooling and was recrystallized from alcohol $(60 \mathrm{ml}$.$) yielding colourless prisms ( 1 \cdot 8 \mathrm{gm}$. m.p. $185^{\circ}$ (found: C, 50.8; H, 4.0; N, 17.9; S, 13.5 per cent).

Henry MCIluain

(Leverhulme Research Fellow)

Department of Bacterial Chemistry

(Medical Research Council),

Bland Sutton Institute of Pathology,

Middlesex Hospital,

London, W.1.

Oct. 19.

${ }^{1}$ McIlwain, H., Brit. J. Exp. Path., 21, 136 (1940).

${ }^{2}$ Woods, D. D., Brit. J. Exp. Path., 21, 74 (1940).

${ }^{3}$ Fildes, P., Lancet, i, 955 (1940).

- Walker, J., J. Chem. Soc., 686 (1940).

${ }^{5}$ Gray, W. H., J. Chem. Soc., 1202 (1939).

- Buttle, G. A. H., Gray, W. H., and Stephenson, D., Lancet, i, 1286 (1936).

'Clemo, G. R., Mcllwain, H., and Morgan, w. MeG., J. Chem. Soc., 610 (1936).

\section{An Electron Diffraction Study of the Surface of Magnesium attacked by an Aqueous Chloride Solution}

Ir is well known that magnesium is vigorously corroded by an aqueous chloride solution. However, previous investigations have always been macroscopic, and did not touch the mechanism of the phenomenon directly. The present study by electron diffraction may provide a fuller knowledge of this phenomenon than hitherto.

In the first stage of corrosion by a chloride solution, simultaneously with the evolution of hydrogen gas, the magnesium became covered with a black porous substance, and then the dark-coated surface in turn became coated with a white porous substance. Upon examining both the black and the white substances by the reflection method of electron diffraction, it was found that they are one and the same, consisting of crystals of magnesium hydroxide, $\mathrm{Mg}(\mathrm{OH})_{2}$, and oxide, $\mathrm{MgO}$; the hydroxide, according to the intensity of the diffraction rings, being present in a slightly larger quantity than the oxide.

Now it is known that magnesium is scarcely corroded in water, and it has been suspected that some sort of a protective film must exist on the surface. This surface film was detected by electron diffraction, which revealed the existence of a mixture of the $\mathrm{Mg}(\mathrm{OH})_{2}$ crystals (large amount) and the $\mathrm{MgO}$ crystals (moderate amount). Therefore, the $\mathrm{Cl}-$ ion plays the part of a catalyst in the reaction between magnesium and water, producing magnesium hydroxide and oxide. The diffraction rings from the surface substances produced in water are not so sharp as those from the substances produced in a chloride solution; hence the crystal size of the former is smaller than that of the latter. Using the equation for crystal size introduced by $M$. von Laue in 1926 , that for the magnesium hydroxide is about $50 \mathrm{~A}$., while that for the magnesium oxide is about $70 \mathrm{~A}$.

It is a pleasure to acknowledge that this work has been done under the direction of Dr. Ichiro Iitaka.

Shigeto Yamaguchi.

Institute of Physical and Chemical Research, Tokyo.

Sept. 24.

\section{Blunted Teeth of Lymnæidx}

EXAMINATION of the anterior extremity of the radula of Lymnæidx reveals a few 'blunted' teeth, but there are sometimes thirty to forty rows of worn teeth in an old mollusc, as seen among the late Prof. Gwatkin's material at the Natal Museum.

Older specimens also contain more rows of teeth than immature ones. New rows are added from the nascent posterior border and the number of tricuspid teeth is increased by coalescence of the cusps of marginal teeth.

Invertebrate teeth are more likely to grow than those of vertebrates which have erupted, and shedding of molluscan teeth is a less frequent process than is commonly supposed.

Britannia Buildings, F. Gordon Cawston.

West Street,

Durban.

Sept. 17. 